\title{
Ficção e filosofia em Las Conversaciones de César Aira
}

Luciene Azevedo

Recebido em: 24 de novembro de 2017

Aceito em: 24 de tevereiro de 2018
Luciene Azevedo é professora de Teoria Literária da Universidade Federal da Bahia. Co-organizou o e-book Autoria e escrita não-criativa (e-galáxia, 2018) e o livro Palavras da Crítica Contemporânea (Paralelo13S, 2017) Contato: aaluciene@gmail.com Brasil 
PALAVRAS-CHAVE: ficção; verossimilhança; César Aira.

KEYWORDS: fiction; verisimilitude; César Aira.
Resumo: A teorização sobre a mímesis, e também o que mais tarde viríamos a chamar de literatura, nasce sob o signo da desconfiança do olhar do filósofo. Assim, tomando como ponto de partida uma breve reflexão sobre a noção de verossimilhança a partir de passagens dos clássicos como A República de Platão e Poética de Aristóteles, o ensaio comenta o romance Las conversaciones (2007) de César Aira com o objetivo de analisar por meio da obra do autor argentino a continuação do diálogo entre a ficção e a filosofia. Apostamos, então, que se a remissão metaficcional, presente em muitas das obras do autor argentino e uma marca de sua assinatura como escritor, pode constituir parte de um projeto literário, também é oportunidade para a reflexão mais ampla sobre o modo de funcionamento da literatura, sobre as relações com o realismo e o elogio dos mundos imaginados pela ficção.

Abstract: The theorization on mimesis, and also on what we would later call literature, arises under the sign of distrust of the philosopher's gaze. Thus, taking as a starting point a brief reflection on the notion of verisimilitude from passages of the classics like The Republic of Plato and the Poetics of Aristotle, this essay comments on the novel Las conversaciones (2007), by César Aira, with the aim of analyzing, through the work of the argentinian author, the continuation of the dialogue between fiction and philosophy. We argue, then, that if the metafictional strategy - present in many of Aira's works, and very common to his signature as a writer - can be part of a literary project, it is also an opportunity for a broader reflection on the workings of literature, on the relations between literature and realism, and on the praising of the worlds imasined by fiction. 
"Dentro del realismo de lo que pasa, está la invención de lo que pasó."

Todos sabemos da longa tradição que aproxima a filosofia e a literatura, ainda que essa relação tenha começado marcada pela rivalidade. Platão, que ficou célebre pela expulsão dos poetas de sua república ideal, explorou a forma do diálogo socrático para convencer sua audiência de que Homero era um mero fazedor de "fábulas falsas" (Platão, 2006, 86), apesar de admitir o fascínio que seus versos eram capazes de despertar. Tal fascínio se tornava mais perigoso pois era creditado ao poder da criação de simulacros próprio à mímesis. Mas é o próprio Platão o primeiro a valer-se da mímesis como estratégia de convencimento. Criando todo o teatro do diálogo, no capítulo $\mathrm{X}$ d' $A$ República, Sócrates expóe a Glauco a teoria dos três níveis. O primeiro nível corresponde ao mundo das Ideias que é o lugar do verdadeiro conhecimento, onde se localiza a essência, domínio por excelência do filósofo, amigo do saber. O segundo nível é o mundo de quem apenas pode copiar a Ideia, o mundo dos artesãos. Mas há ainda um terceiro nível de distanciamento da verdade: esse é o lugar do poeta, do mero criador de aparências, capaz de elaborar todo um mundo de falsidades: uma espécie de artífice que "faz tudo que nasce da terra, dá forma a todos os seres vivos, a ele próprio e o que mais houver, além de ser o autor da terra, do céu e dos deuses" (Platão, 2006, 228).

$\mathrm{Na}$ condição de simulacro, a teorização sobre a mímesis, e também o que mais tarde viríamos a chamar de literatura, nasce, pois, sob o signo da desconfiança do olhar do filósofo. 
Como cópia degradada da essência, da Ideia, a mímesis mostra sempre um déficit em relação ao modelo. E é isso que Platão não pode perdoar. Mal sabia que séculos depois é exatamente essa condição de distanciamento, agora valorizada, a que seria responsável por circunscrever o território do ficcional. Sugerindo o que chamou de a "reversão dos simulacros", Deleuze afirma a potência do simulacro, libertando-o da submissão ao modelo, pois o simulacro "não é uma cópia degradada, ele encerra uma potência positiva que nega tanto o original como a cópia" (1974, 267), afirma o filósofo francês.

Ninguém parece ter explorado com mais tranquilidade esse funcionamento da ficção do que Jorge Luis Borges. Apostando no simulacro, Borges náo apenas aparece ficcionalizado em seus contos, mas é reconhecido por explorar os limites entre a ficção e a realidade ao resenhar livros inexistentes e aproveitar episódios reais como matéria de suas ficções.

Uma de suas "ficçôes verdadeiras", como as chama Tomás Eloy Martínez (2006), ou "biografias infames", como as nomeia o próprio Borges, pode ser um bom exemplo da exploração da "potência positiva" do simulacro a que se refere Deleuze. Trata-se do conto "O impostor verossímil Tom Castro" que aparece em História Universal da Infâmia (2012). Baseando-se em um episódio verídico, Borges explora as inverossimilhanças da realidade. Trata-se da troca improvável de identidade entre um aristocrata inglês criado na França, Sir Roger Charles Tichborne, e um açougueiro que, embora registrado como Arthur Orton, assume o nome de Tom Castro. A troca acontece depois que a mãe de Tichborne, sem acreditar no comunicado sobre a morte do filho em um naufrágio nas costas do Rio de Janeiro, coloca um 
anúncio na tentativa de encontrá-lo vivo. Mas o que interessa a Borges no episódio é um terceiro personagem chamado Bogle que, segundo o autor argentino, é o gênio responsável pelo que chama de "projeto de insensata perspicácia” (Borges, 2012, 328). E em que consiste tal perspicácia? Segundo Borges, "Bogle sabia que um fac-símile perfeito do desejado Roger Charles Tichborne era de impossível obtenção. Sabia também que todas as similitudes conseguidas não faria outra coisa senão destacar certas diferenças inevitáveis. Renunciou, pois, a toda semelhança” (Borges, 2012, 328) e instruiu Tom Castro a se apresentar como o outro. Além dessa jogada de mestre, Borges afirma que o plano foi facilitado pela disposição da mãe em receber o filho pródigo, quem quer que ele fosse, e pela colaboraçáo do tempo, pois já haviam se passado 14 anos do desaparecimento do filho. $\mathrm{O}$ final da história não é feliz para o impostor: depois da morte de seu mentor, Tom Castro não consegue manter a farsa, é reconhecido como impostor e condenado à prisão.

Mas o que me interessa destacar é o motivo do elogio borgeano à estratégia de construção da verossimilhança por Botle em relação ao caso. Ao invés de tentar maquiar uma semelhança improvável e inexistente, o estrategista faz do inverossímil, verossímil, afastando a comparação entre o original e a cópia pelo abismo da criação de um simulacro que não encontra objeto de comparação possível já que Tichborne "era um esbelto cavalheiro de ar retraído, traços agudos, tez morena, cabelo negro muito liso", enquanto Tom Castro apresentou-se como um Tichborne "balofo, com sorriso amável de imbecil, cabelo castanho e uma inalterável 
ignorância do idioma francês" (Borges, 2012, 328). Borges insiste que a longevidade da farsa só se explica pela astúcia sutil de Botle de rejeitar a emulação do Tichborne original, acreditando que a própria diferença em relação a ele seria capaz de garantir a verossimilhança. O que Borges chama de "as virtudes da disparidade" pode também abrir caminho para uma reflexáo filosófica sobre a construção da verossimilhança narrativa e para o modo de funcionamento da literatura.

É esse o mote que gostaria de explorar comentando um romance de outro argentino: César Aira. E aqui chegamos também a outro viés desse texto: o comentário sobre um romance ou romancezinho, como o próprio autor costuma referir-se a suas produçóes, intitulado Las conversaciones. Nessa narrativa, Aira parece retomar e expandir os pressupostos presentes no conto borgeano ao fazer seu narrador afirmar que "a ficção criava um mundo segundo e simultâneo" (Aira, 2007, 23), tal como Tom Castro parece se colocar em relação a Tichborne.

Se meus pressupostos têm alguma validade, Aira, então, constrói por meio dessa narrativa uma elaborada reflexão sobre a condição da literatura.

Mas antes de comentar com mais vagar a obra, vale a pena apresentar o escritor. Aira, um argentino de Pringles, é um autor muito particular no contexto contemporâneo da literatura, e não apenas da literatura latino-americana. O autor defende a ideia do que chama de "má literatura", por escrever compulsivamente, "sempre para adiante". Reconhecido pela crítica pelos finais abruptos de seus livros, por certa idiotia que alimenta muitas das peripécias de seus relatos, pelo cultivo de uma mitologia própria em relação 
a sua condição de escritor, Aira já publicou mais de 80 títulos pelas mais diversas editoras, desde os grandes conglomerados até editoras alternativas.

Não é incomum encontrar em meio a uma obra que não para de crescer a tematização de seu próprio estilo de criaçáo "o gosto por tramas impossíveis, a precipitação do desenlace, a inclinação pelo desmesurado... a indolência diante da idiotia", como disse Sandra Contreras $(2002,258)$ em uma leitura fundamental à fortuna crítica de Aira. No entanto, o ritmo febril de invenção não se descuida da "sintaxe impecável, [de] uma prosa (...) 'elegante”" (Contreras, 2002, 127).

Se a remissão metaficcional a sua própria assinatura como escritor, presente em muitas de suas obras, pode constituir parte de um projeto literário em andamento, também é oportunidade para a reflexão mais ampla sobre o modo de funcionamento da literatura.

Nesse sentido, Las Conversaciones pode ser lido como um quase romance filosófico que tematiza o modus operandi da ficção. O próprio título já parece remeter aos famosos diálogos platônicos, mas na situação narrada por Aira tudo é bem mais prosaico. Trata-se de um narrador (nunca nomeado) que recém aposentado ocupa-se em sua insônia de reconstituir mentalmente passo a passo as conversas que manteve com amigos em encontros vespertinos.

Se a remissão ao filósofo pode parecer arbitrária, a leitura vai mostrando a formação de uma espiral narrativa que reelabora com escárnio os três níveis platônicos. Embora o narrador afirme que ao relembrar, à noite, as conversas que tivera com amigos à tarde, a memória seja precisa, pois é capaz não somente de recuperar "os temas (...) da conversa, mas também as réplicas, 
uma a uma, até mesmo as vacilaçóes, os balbucios (...) as divagaçóes” (Aira, 2007, 10), logo em seguida reconhece que a memória da conversa tem sua própria potência simulacral, pois afirma que "a lembrança pode ser idêntica ao que é recordado, mas é ao mesmo tempo distinta, sem deixar de ser a mesma” (Aira, 2007, 13).

Ao propor uma semelhança diferida em relação à conversa de fato e sua lembrança, Aira já indica um desvio ao dictum platônico. Mas há ainda uma outra instância, que é a do próprio texto, a do registro escrito que o narrador faz questão de elaborar para nos contar a história de suas conversas com o amigo. E é nesse plano, o da terceira instância do registro escrito, que passamos a acompanhar o processo de elaboração da própria narrativa que nos é contada. Ou seja: acompanhamos um narrador (re)construindo pela imaginação uma situação que é atestada por seu testemunho, mas à qual só temos acesso por meio da narrativa. Tal como o narrador, maravilhado com os poderes da recuperação mnemônica, o leitor pode "ver a cena (...) ainda que não ouvisse as palavras [e] só visse o que evocavam” (Aira, 2007, 28). O poder de constituir uma realidade por meio das palavras, da história narrada, parece o mote do argumento e sela de vez o pacto com a imaginação do leitor que, afinal, não pode acompanhar nem a conversa, nem sua recomposição pela memória, mas apenas a elaboração escrita dela, a leitura do romance que tem em máos.

Aira já afirmou em inúmeras entrevistas que não lhe interessa nem um pouco a história e que não costuma se preocupar com o quê contar. Em As conversaçôes ao fim e ao cabo o leitor fica com a impressão de que nada 
aconteceu, pois a história resume-se a isso: um homem que escreve sobre seu hábito de rememorar as conversas que costuma ter com os amigos. Mas a mágica das narrativas de Aira parece residir nesse ponto: de muito pouco, ou do que parece incapaz de render uma história, nasce todo um mundo.

$\mathrm{O}$ narrador detém-se a explicar como em uma das conversas, em meio às muitas "consideraçóes sobre o mundo" (Aira, 2007, 17), surge um impasse. Zapeando ao azar pelo menu de canais da tevê a cabo, o narrador começa a assistir a um filme que incorpora todos os clichês da indústria hollywoodiana. Em meio ao tédio, o narrador presencia uma cena que justifica toda a conversa na qual a narrativa se espraia: em um cenário montanhoso da Ucrânia, o ator que representa um pastor de cabras está usando um relógio caríssimo, de uma marca famosa, um Rolex.

Comentando com escárnio durante a conversa com um amigo, a situação que julga inverossímil, fica perplexo ao perceber que seu interlocutor não vê qualquer indício de inverossimilhança na cena, respondendo ao narrador: "Que havia de estranho no fato de que o protagonista do filme usasse esse relógio ou qualquer outro? Nós mesmos não usamos relógio?” (Aira, 2007, 15).

Depois de se referir à incongruência de que era um pastor de cabras, adepto da cultura de subsistência, fiel aos costumes ancestrais de guiar-se pela luz do sol, vivendo isolado nas montanhas portar um objeto tão luxuoso, e ainda assim não conseguir o assentimento de seu amigo, o narrador passa a considerar que poderia ter havido um erro de descontinuidade, algum descuido da produção, uma distração do diretor do filme que acabou permitindo a falha. 
Mas o amigo não é capaz de aceitar quaisquer dos argumentos e se mantém firme na defesa da razoabilidade do fato de que o pastor usava um Rolex, acrescentando ainda que o ator que o representava era um homem muito rico: "tinha tanto dinheiro que todos os anos da sua vida não seria suficiente para contá-lo" (Aira, 2007, 22), afirma o amigo do narrador.

Colocando em dúvida a inteligência do amigo, ao narrador só lhe ocorre explicar o que lhe parece óbvio: "o ator não é o personagem”. Mas ao mesmo tempo, evitando ferir o orgulho do interlocutor, dispara em elucubraçôes sobre a vida de um ator de Hollywood, imaginando o assédio das mulheres, dos diretores com a oferta de roteiros repetitivos, as viagens a trabalho... Tudo isso ocupa muitas páginas que o narrador assume como uma "ficção, uma história que não tinha acontecido” (Aira, 2007, 28) pois, afinal, não fazia mais parte das conversas mantidas nos encontros à tarde com seu amigo mas, sim, compunha a reflexáo disparada pela manifestaçáo da ignorância de seu interlocutor.

Enquanto isso, nós, leitores, já avançamos quase até a metade da história da qual o narrador afirma que está pondo muito dele em tudo (Aira, 2007, 31) e que, em especial, em relação à imaginação sobre o modo de vida de um ator "quanto mais dados lançava para arredondar sua figura de 'ator', mas 'personagem' era" (Aira, 2007, 33) de uma história própria, uma história inventada, portanto, cada vez mais afastada da reprodução fiel de qualquer conversa. Enfim, aos poucos o leitor vai se dando conta de que também está convidado a participar das conversaçóes e a acompanhar, simultaneamente, não apenas o processo de construção da verossímil narrativo da própria 
narrativa que lemos, pois nos damos conta de que se trata de uma história dentro da outra, mas também a refletir sobre a natureza do verossímil.

Já que evocamos Platão, não podemos deixar de falar de um discípulo famoso. A Poética de Aristóteles pode ser lida como uma réplica à visão de Platão sobre a mímesis. Em seu tratado, o estagirita cunhou a célebre distinção entre o poeta e o historiador, atribuindo àquele "não o ofício de narrar o que aconteceu; mas, sim, o de representar o que poderia acontecer, quer dizer: o que é possível segundo a verossimilhança” (Aristóteles, 1992, 50). A releitura moderna da Poética atribui a Aristóteles um protagonismo no reconhecimento da autonomia do universo literário. É esse preceito que parece sustentar a arrogância do narrador ao avaliar a idiotia do amigo ao não reconhecer o absurdo da existência de um Rolex no braço de um pastor de cabras, pois isso forçaria a quebra de qualquer suspensão da descrença que mesmo o espectador dos mais banais filmes do mainstream está disposto a aceitar.

Mas o problema ganha novos contornos e a história sofre uma reviravolta. Se o verossímil é descrito pelo narrador como "um nome convencional que cobria tudo o que dizia respeito ao homem na sua guerra perene contra o absurdo" (Aira, 2007, 35), a réplica do amigo toca o que parece o cerne da questão: afinal, o que é o verossímil? Para o amigo, o erro do narrador “consistia em limitar [se] a uma concepção estática do verossímil” (Aira, 2007, 48) pois, no seu entendimento, o "verossímil podia ser, e era, um gerador de histórias" (Aira, 2007, 48).

Aqui, o amigo parece tomar Aristóteles como farol, pois é ele quem afirma o que parece uma contradição ao asseverar na sua Poética que 
"verossimilmente muitos casos se dão e ainda que contrários à verossimilhança” (Aristóteles, 1992, 109).

Para provar a relativização do absurdo, as réplicas do amigo rememoradas pelo narrador investem em um caudal vertiginoso de possibilidades que ironiza a quantidade de peripécias absurdas dos filmes comerciais para o público de massa simulando a "habilidade com que se tornava verossímil o absurdo folhetinesco" (Aira, 2007, 77). Mas o narrador só fica convencido da labilidade do verossímil quando a história sofre uma reviravolta: depois de o narrador e seu amigo esgotarem todos os recursos para defenderem suas posiçóes, descobrem casualmente que o filme que estavam discutindo era um exemplo clássico do filme dentro do filme, já que o pastor de cabras, na verdade, interpretava na cena o papel de um ator contratado para resolver uma trama de espionagem.

E aqui lembramo-nos da metáfora usada por Platão condenando a criação mimética por parecer um espelho que apenas simula a imagem da realidade. Se Platão usa a comparação para desprestigiar o poeta, no caso de Aira o jogo de espelhos entre a conversa dos dois amigos sobre a trama de um filme B e a reflexão sobre a criação mimética, que vai emergindo como uma história secreta na superfície da narrativa à maneira de uma história dentro da outra, configura-se como um elogio à natureza da mímesis.

Explicando melhor: depois do esclarecimento a respeito do mal entendido, que, na verdade, é apenas parte da engenhosa peripécia que Aira constrói para o desfecho da história, o fato de que o personagem é, na verdade, um ator que, na cena do filme, se faz passar por um pastor torna aceitável o uso do 
Rolex. O episódio tratado desde o início pelo narrador como comprometedor da coerência narrativa (já que um pastor não poderia usar um Rolex, segundo as regras do senso comum realista) ganha uma verossimilhança aceitável não só no contexto da coerência da cena do filme sob análise nas conversas entre os amigos, mas também para a história que lemos, o livrinho de César Aira que temos em mãos. Depois de acompanharmos páginas e páginas das mais disparatadas elucubraçóes do narrador e de seu amigo - cada um deles tentando defender sua posição a respeito da possibilidade ou não do uso de um relógio caro usado por um pastor de cabras -, o que parece embromação, idiotia, vacuidade, enfim, perda de tempo (afinal, o leitor se pergunta: aonde tudo isso vai dar?), desdobra-se na descoberta para o leitor de que o verossímil não se reduz a um mecanismo que assegura o mero realismo da história, mas que é, por excelência, o mote gerador de narrativas, o detalhe "emergencial que acontecia no último momento" e arma todo o arcabouço da reflexão sobre o funcionamento da ficção.

Todo o motivo da conversação, todo a motivação para a própria narrativa que lemos, então, é originado em um erro, mas ainda assim o narrador insiste que "dessa operação podia sair o interesse e a novidade da história" (Aira, 2007, 49).

E quais são mesmo esse interesse e essa novidade? Mais uma vez, a resposta está nas palavras do narrador: "o terreno que cultivávamos não era o da ficção já dada e que se consume como pipoca, mas o da sua criação" (Aira, 2007, 58). Defendendo a possibilidade de uma coerência criada pela própria obra, que desobedece ao verossímil realista, Aristóteles absolve o "poeta [que] 
representou impossíveis", afirmando que “é um erro - desculpável, contudo, se atingiu a finalidade própria da poesia, e se, de tal maneira, resultou mais impressionante essa parte do poema" (Aristóteles, 1992, 164).

A finalidade dessa narrativa de Aira parece estar em provar como as histórias precisam de muito pouco para serem contadas: apenas um erro de atenção enquanto assiste-se a um filme B basta para levantar uma discussão sobre o "frágil fio de aranha com o qual a ficção ata a realidade" (Aira, 2007, 67) e para fazer da verossimilhança um artifício poderoso que assegura a potência ficcional.

Aira parece, então, reelaborar por meio da ficção o posicionamento aristotélico sobre a verossimilhança entendida não como garantia de realidade, mas como artifício, criação de procedimento fundamental à trama, "força inventiva que faz com que o impossível torne-se a própria lógica da narrativa" (Sager, 2014, 65).

Desse modo, Aira parece também responder a certa tendência da crítica em identificá-lo como um provocador do absurdo narrativo. Não é difícil encontrar comentários sobre a obra do autor que assinalam como experiência de leitura comum a suas obras a sensação de que o "relato perde o controle e o rumo e não termina bem", deixando ao leitor a impressão de que o "romance deu errado" (Contreras, 2002, 127). Podemos dizer que esse é um resultado essencial para muitas de suas produçóes e que é cultivado como "estilo" pelo próprio Aira mas em Las Conversaciones, o autor parece romper com essa expectativa, apresentando uma série de formulaçóes sobre o modo como a ficção é responsável por criar todo um mundo através da 
invenção de um verossímil próprio e não o verossímil no sentido leigo da palavra, cujo parâmetro costuma ser o que reconhecemos como realidade, não o que o narrador chama de um "verossimil chato e estático", mas o "erro possível" dentro do próprio ficcional, capaz de inventar um mundo feito de palavras. Ou como afirma a crítica argentina Beatriz Sarlo: "A imagem de um pastor de cabras ucraniano com um Rolex no braço não é verossímil nem inverossímil em si mesma, mas dependente do contexto ficcional” (2008).

Para além de assegurar o reconhecimento de um verossímil próprio ao texto, como parece em questão na leitura moderna de Aristóteles, a reflexão de Aira avança na dúvida a respeito da própria natureza do verossímil, maleável e relativa pois, como afirma Sarlo, "para que algo seja julgado verossímil ou inverossímil é indispensável saber em qual nível de "realidade" se inscreve"(2008): se naquele em que comumente costumamos identificar como nosso mundo real ou se nos referimos a uma realidade elaborada pela linguagem.

É claro que atrelada à discussão sobre o verossímil está a noção de realismo. $\mathrm{O}$ próprio narrador não ignora essa relação, pois afirma que "entre a ficção e a realidade havia uma instância intermediária que as articulava: o realismo" (Aira, 2007, 71). Devemos aos pós-estruturalistas o entendimento do realismo como uma convenção de linguagem. Aira parece ciente disso, mas tampouco abona integralmente a noção de efeito de real barthesiana, por exemplo. Todos devem se lembrar da análise feita por Barthes do conto flaubertiano "Um coração simples”. Logo no início da narrativa, Barthes chama a atenção para uma "notação insignificante" $(2004,36)$ : a menção a um barômetro colocado acima do piano em que se apoia uma pilha de 
livros, objetos que compóem o cenário da casa em que Felicité trabalha. Considerando o modo de funcionamento das descriçóes para o realismo do século XIX, o barômetro não passa de um "enchimento", um excesso descritivo, um "excesso de representação das coisas" (Rancière, 2010, 77), mas a argumentação de Barthes (2004) trabalha para encontrar uma razão de ser moderna para o verossímil realista que não seja a mera autenticação do real, o "ter-estado-lá" das coisas. Se essa visão do realismo parece anos luz afastada do procedimento de Aira, tampouco o argumento de Barthes parece suficiente para explicar as implicaçóes que a verossimilhança e o realismo mantêm para a ficção do autor argentino. Para Barthes, a noção de "efeito de real" diz respeito a uma ruptura com o significado da denotação que é conferido pela referencialidade. Trocando em miúdos: a ilusão referencial, a ideia de que o texto literário encontra sua âncora de sentido no referente real é uma noção improvável para as formas estéticas da modernidade. Assim, o "efeito de real" é a reinvençáo do verossímil como conquista da autonomia artística. Embora o romance de Aira abone essa compreensão, parece rechaçar certa simplicidade subjacente à crença de que a realidade possa ser retirada da equação quando se pensa a ficção e é o narrador de Las Conversaciones que expóe para o leitor essa relaçấo como um problema quando afirma que "a diferença entre a ficção e a realidade não era um assunto pontual... era mais como uma mancha de azeite, se estendia a tudo" (Aira, 2007, 44). Isso quer dizer que Aira, ao defender a existência de um verossímil próprio à elaboração imaginativa, não abandona a preocupação com a inserção desse mundo no mundo que reconhecemos como real ou, tal como afirma Jacques 
Rancière, "a questão da ficção contém dois outros aspectos entrelaçados entre si. A ficção designa certo arranjo dos eventos, mas também designa a relação entre um mundo referencial e mundos alternativos" (2010, 80).

Lido dessa maneira o diálogo com a filosofia na ficção de Aira resgata os primeiros esboços de explicação sobre a mímesis presentes em Platão e Aristóteles, e celebra a relação entre o mundo referencial e o mundo imaginado onde se tramam as "manobras da verossimilhança" (Aira, 2007, 71).

O narrador, já no fim do romance, ao se dar conta de que o erro de interpretação que dá origem ao imbroglio narrativo que estamos terminando de ler pode ser uma consequência das inúmeras interrupções que tem de fazer enquanto está assistindo ao filme - já que vai ao banheiro, fala ao telefone com um amigo e discute com a mulher -, afirma que a maneira entrecortada como acompanha o desenrolar da narrativa televisiva é uma forma suspensiva de prestar atenção às coisas muito semelhante à realidade, muito própria de nossa vida cotidiana, pois "todo o tempo estamos perdendo coisas importantes, elos essenciais para entender o grande relato geral” (Aira, 2007, 104). E se a ficção não serve para nada, como afirmava Platão, ou é apenas gratuita, como assevera o narrador do romance, é porque não tem a pretensão ou o poder de explicar a vida, mas apenas de construir imaginativamente uma perspectiva parcial e imperfeita, como qualquer outra, a respeito do que chamamos de realidade. $\mathrm{Na}$ leitura filosófica que a literatura de Aira faz da ficção, todo escritor é um fingidor, e isso é um elogio. 


\section{REEERÊNCIAS BIBLIOGRÁFICAS}

Aira, César. Las Conversaciones. Rosario. Beatriz Viterbo: 2007.

Aira, César. Copi. Rosario. Beatriz Viterbo: 1991.

Aristóteles. Poética. Trad. Eudoro de Souza. São Paulo. Ars Poética:1992.

Barthes, Roland. "O efeito de real". In: O rumor da língua. Trad. Mário Laranjeira. Sáo Paulo. Cultrix: 2004.

Borges, Jorge Luis. História Universal da Infâmia. Trad. Davi Arrigucci Jr. São Paulo. Companhia das Letras: 2012.

Contreras, Sandra. Las vueltas de César Aira. Rosario. Beatriz Viterbo: 2002.

Deleuze, Gilles.. "Platão e o simulacro". In: Lógica do sentido. São Paulo: Perspectiva: 1974

Martínez, Tomás Eloy. Ficciones verdaderas. Hechos reales que inspiraron grandes obras literarias. Planeta, Buenos Aires: 2006.

Platão. A República. Guinsburg, Jacó (org. e tradução). São Paulo. Perspectiva: 2006.

Rancière, Jacques. "O efeito de realidade e a política da ficção". In: Novos estudos - CEBRAP no. 86 São Paulo Mar. 2010. http://dx.doi.org/10.1590/S010133002010000100004. (04-11-2017).

Sager, Valeria. El punto en el tiempo: Realismo y gran obra en Juan José Saer y César Aira (Tesis de posgrado). Presentada en Universidad Nacional de La Plata. Facultad de Humanidades y Ciencias de la Educación para optar al grado de Doctora en Letras. 2014. http://www.memoria.fahce.unlp.edu.ar/tesis/te.1079/ te.1079.pdf (04-11-2017).

Sarlo, Beatriz. “¿Cuánta invención es posible?”. In: Diário Perfil, Buenos Aires, 07-02-2008. 